\title{
Failure of two progesterone antagonists, mifepristone and onapristone, to affect luteal activity in lactating rats
}

\author{
P. van der Schoot, J. Th. J. Uilenbroek and E. J. Slappendel \\ Department of Endocrinology Growth and Reproduction, Faculty of Medicine, \\ Erasmus University Rotterdam, PO Box 1738, 3000 DR Rotterdam, The Netherlands
}

\begin{abstract}
Summary. The progesterone antagonists, mifepristone (RU-38,486) and onapristone (ZK-98,299), given as $2 \mathrm{mg}$ daily, did not markedly affect lactation in rats. Both litter growth and time spent by 10-pup litters attached to their mothers were similar in antagonist-treated mothers and in solvent-treated controls. The progesterone antagonists did not affect the steroid content in corpora lutea remaining from the preceding pregnancy. Corpora lutea formed after post-partum ovulation also showed nearly normal function throughout the first $\mathbf{1 7}$ days of lactation. It is concluded that progesterone itself plays no role in the initiation or maintenance of luteal function when prolactin secretion is governed through an action independent of the ovaries, as through suckling.

Antagonist-treated rats ovulated around Day 13 of lactation despite suckling. This ovulation was not associated with a decrease of progesterone production by the corpora lutea formed after post-partum ovulation. Apparently, elimination of progesterone action may protect corpora lutea from luteolysis. The latter finding indicates a possible role of progesterone in luteolysis and deserves further analysis.
\end{abstract}

Keywords: lactation; anti-progestagen; mifepristone; onapristone; luteolysis; rat

\section{Introduction}

Progesterone is, quantitatively, the most important physiologically active steroid of ovarian origin. The recent availability of progesterone antagonists has renewed interest in the investigation of the physiological role(s) of progesterone in the regulation of ovarian activity (Philibert et al., 1985; Baulieu, 1985). Equivocal results have been reported with respect to effects of progesterone antagonists on disruption of luteal function, as measured by blood concentrations of progesterone, in women and nonhuman primates (Herrmann et al., 1982; Asch \& Rojas, 1985; Shortle et al., 1985; Schaison et al., 1985; Puri et al., 1988).

In rats, daily treatment with mifepristone (RU-38,486, Roussel-Uclaf, France) results in the maintenance of corpora lutea while ovulations continue: consequently, during treatment with mifepristone rats show ovarian enlargement due to accumulation of progesterone-producing corpora lutea (Philibert et al., 1985; van der Schoot et al., 1987a). In contrast, mifepristone was reported to induce luteolysis in early pregnant or pseudopregnant rats (Kawano et al., 1988; Singh et al., 1988). In guinea-pigs an anti-luteolytic action of onapristone was observed, possibly mediated through an effect on uterine prostaglandin secretion (Elger et al., 1987, 1988). Paradoxically, these observations are consistent with both luteolytic and anti-luteolytic actions of progesterone antagonists.

Luteal activity during pseudopregnancy in rats is dependent on hypersecretion of pituitary prolactin, either in pulsatile fashion as seen during copulation-induced pseudopregnancy (Freeman \& Neill, 1972; Gunnet \& Freeman, 1983) or continuously as seen during pseudopregnancy induced by ectopic pituitary grafts (de Greef \& Zeilmaker, 1978) or lactation (van der Schoot et al., 1978). 
Evidence has been presented that progesterone plays a role in the initiation and/or maintenance of pituitary prolactin secretion required to sustain pseudopregnancy (de Greef \& Zeilmaker, 1978). It is therefore possible that, during pseudopregnancy, the administration of a progesterone antagonist will affect progesterone-dependent secretion of prolactin and, subsequently and therefore indirectly, induce luteolysis.

Potentially direct effects of progesterone antagonists on rat corpora lutea in vivo can perhaps be better examined if secretion of prolactin is sustained by a mechanism independent of ovarian hormone secretion. Lactation in rats presents an example of such situation: lactation is known to be associated with luteal activity and this activity is primarily controlled by the suckling stimulus. Ovarian hormones during normal lactation do not influence lactational performance nor do they affect the pattern of suckling or secretion of pituitary prolactin (van der Schoot \& de Greef, 1983). Treatment with mifepristone only marginally affects litter growth (van der Schoot et al., 1987b).

We therefore examined luteal activity in lactating rats and the potential effects of progesterone antagonists on it. Lactating animals were expected to offer the possibility of studying various potential actions of progesterone antagonists on corpus luteum function. Firstly, the corpora lutea resulting from post-partum ovulation (on Day 2 of lactation) can be analysed with respect to their development and function while they have been exposed to the antagonists from early in their development. Secondly, the corpora lutea of the preceding pregnancy slowly decrease in size and functional activity during the ensuing lactational period (Long \& Evans, 1922). Effects of progesterone antagonists on these corpora lutea can be analysed through examination of their rate of disappearance from the ovaries and their contents of steroids.

\section{Materials and Methods}

Animals. The experiments were performed with commercially obtained 3-month-old rats of Wistar origin (TNO, Rijswijk, The Netherlands). The animals were housed in $14-\mathrm{h}$ light and $10-\mathrm{h}$ darkness per day and were given free access to pelleted food and tap water. The rats were impregnated by locally bred male rats of proven fertility. Pregnant rats were housed individually from 2-3 days before expected parturition. Rats were included in the experiments only if they gave birth to litters of 9 or more pups (day of parturition = Day 1 of lactation).

On the day after parturition litters were adjusted to 10 pups and the rats were, at random, allocated to one of three treatment groups. Group 1 (control) included animals which were given one daily s.c. injection of $0.1 \mathrm{ml}$ olive oil. Animals in Group 2 received a daily injection of $0.1 \mathrm{ml}$ oil containing $2 \mathrm{mg}$ of a microcrystalline suspension of mifepristone (Roussel-Uclaf, Romainville, France). Rats in Group 3 received $0.1 \mathrm{ml}$ oil containing $2 \mathrm{mg}$ onapristone (Schering, Berlin, West Germany). There were 8 rats in each of Groups 1, 2 and 3.

Litter weight was recorded daily. Vaginal smears were taken to record the occurrence of vaginal cornification: in an earlier study cornified vaginal smears occurred in antagonist-treated rats from around Day 12 of lactation (van der Schoot et al., 1987b).

Ovarian activity during lactation. On Day 8 of lactation blood was taken from all rats. The left ovary was removed and the ovarian weight recorded. In the ovaries the corpora lutea of the preceding pregnancy could be recognized macroscopically as pale large structures and the corpora lutea of lactation as large reddish structures. All corpora lutea were dissected out and weighed on a torsion balance. From each category 4 corpora lutea were homogenized individually in $1.0 \mathrm{ml}$ ethanol: the homogenates were kept at $-20^{\circ} \mathrm{C}$ for the later determination of their contents of progesterone and $20 a$-dihydroprogesterone.

Rats treated with the progesterone antagonists were killed 5 days after the first occurrence of a cornified vaginal smear. Control rats were killed on Day 17-18 of lactation which was on the same days of lactation as the antagonisttreated rats. At autopsy the remaining ovary was removed and the corpora lutea were dissected. Corpora lutea from the preceding pregnancy were identified as small brownish structures and corpora lutea of lactation as large reddish structures. Several rats treated with the antagonists showed signs of recent ovulation and so 3 generations of corpora lutea were present in the ovary.

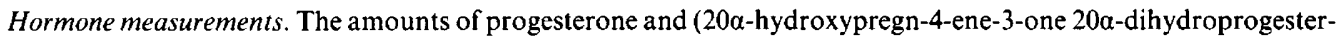
one) in blood and corpus luteum homogenates were measured by radioimmunoassay following the procedure described by Uilenbroek et al. (1989). The intra- and inter-assay variations were $8 \%$ and $20 \%$ respectively. The measurements in blood were made after extraction. The recovery of radioactively labelled progesterone or $20 \alpha$-dihydroprogesterone from the extraction procedure was $80 \%$ or more. The possible interference of the administered drugs with the radioimmunoassay procedures for measuring progesterone and $20 \alpha$-dihydroprogesterone in blood was estimated through the measurement of progesterone and 20a-dihydroprogesterone in ovariectomized rats treated for 3 weeks with 
mifepristone or onapristone ( $2 \mathrm{mg} / \mathrm{rat} / \mathrm{day} ; 6$ rats per group) or oil vehicle only. No significant differences occurred between the mean \pm s.e.m. concentrations (nmol/l) of 'progesterone' or ' $20 \alpha$-dihydroprogesterone' between the three groups (progesterone values: oil, $10 \pm 3$; mifepristone, $13 \pm 3$; onapristone, $8 \pm 1 ; P>0.05 ; 20 \alpha$-dihydroprogesterone values: oil, $1.5 \pm 0.3$; mifepristone, $2.4 \pm 0.6$; onapristone, $1.0 \pm 0.2 ; P>0.05$ ). It was concluded that administration of the compounds did not interfere with the radioimmunoassay procedures.

The concentrations of prolactin in blood were measured by a double-antibody radioimmunoassay procedure following the instructions provided by NIADDK and expressed as $\mu \mathrm{g}$ NIADDK-rat Prolactin RP-1 per litre. Intraand inter-assay variation were 10 and $20 \%$ respectively.

Lactational performance. Lactational performance was evaluated in two ways. Firstly, regular weighing of the litters was expected to provide a crude but valid index of the overall adequacy of the lactational performance. Secondly, during the day before autopsy lactational performance was recorded through direct observation of 6 rats in all 3 groups during three periods (late afternoon, midnight, early morning) of $2 \mathrm{~h}$ each. The percentage time was recorded that pups were lying attached to their mother's nipples as well as the number of milk ejections. With regard to the latter, the work of Lincoln et al. $(1973,1980)$ has revealed unequivocally identifiable behavioural characteristics of these events.

Statistical analysis. The results were analysed through one- or two-way analysis of variance and overall differences were further evaluated through the HSD test (Kirk, 1968). Differences between groups were judged significant if their double-tailed probability was $5 \%$ or less.

\section{Results}

\section{Progesterone antagonists and lactational performance}

Litter growth in the three goups of rats is presented in Fig. 1. During the first 10 days of lactation litters grew equally well in all three groups. After Day 10 of lactation, however, the rise in litter weight increase which was observed in oil-treated rats was absent in the rats treated with the progesterone antagonists $(P<0.001)$.

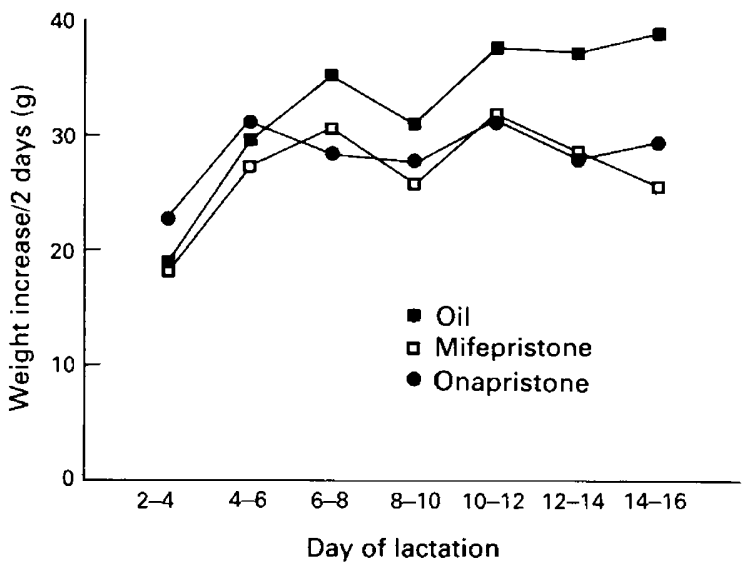

Fig. 1. Litter growth of 10-pup litters with mothers treated, from the day after parturition (Day 1), with oil (control), $2 \mathrm{mg}$ mifepristone/day or $2 \mathrm{mg}$ onapristone/day. Litter growth is equal in the three groups until around Day 10 of lactation. Standard errors were too small $(\leqslant 2 \mathrm{~g})$ to be presented.

Lactational performance on Days 16 and 17 of lactation is depicted in Fig. 2. The percentage time spent by the litters attached to their mothers showed a diurnal rhythm in all 3 groups: there were no significant differences between the 3 groups in the percentage time spent suckling but pups with mothers treated with mifepristone received more milk ejections than did those with mothers treated with onapristone at all times and control mothers at midnight. 

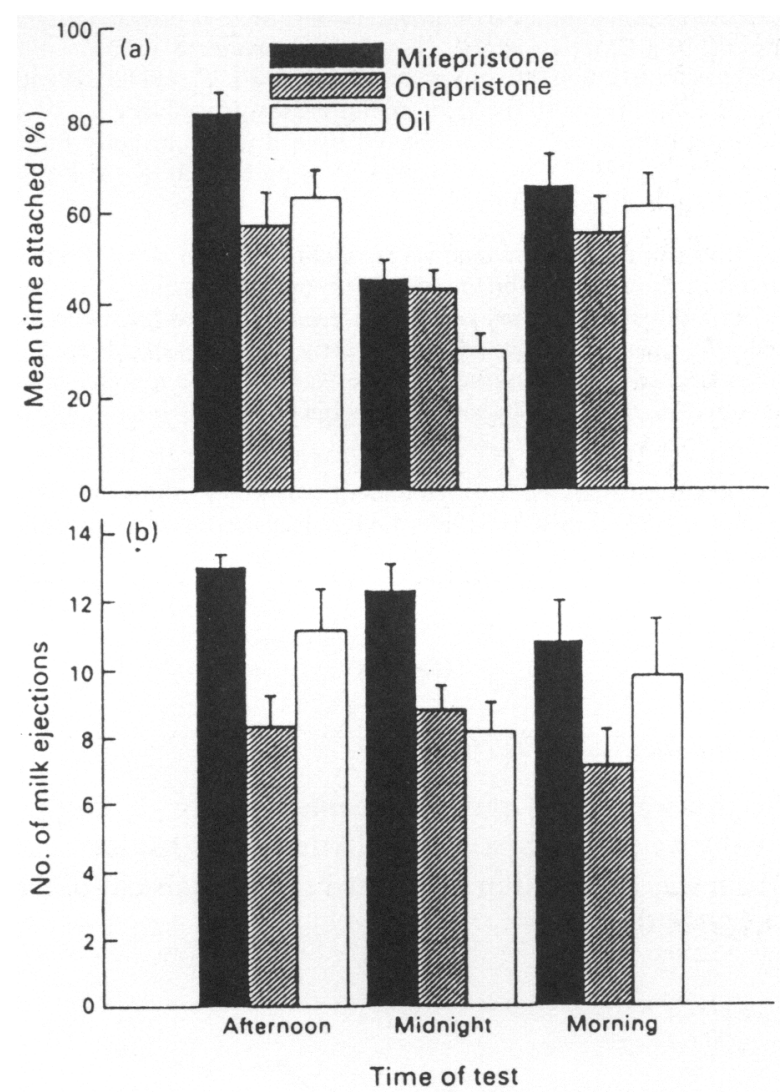

Fig. 2. Lactational performance on Days $16 / 17$ of lactation of rats with 10-pup litters. Lactating rats were treated with oil (controls), $2 \mathrm{mg}$ mifepristone/day or $2 \mathrm{mg}$ onapristone/day. Error bars represent s.e.m. of 6 litters.

Progesterone antagonists, vaginal smear cytology, and the remaining ovarian tissues

Oil-treated control rats showed mucified vaginal smears throughout the period of study. Rats treated with the antagonists showed a cornified vaginal smear on Day 12-14 of lactation. In 8 of these latter rats ( 4 treated with mifepristone; 4 treated with onapristone), 1 day with a cornified vaginal smear was followed by a leucocytic 'metoestrous' smear and further dioestrous smears as after ovulation during a normal ovarian cycle. These rats had ovulated on the day of the cornified vaginal smear as shown by macroscopic and microscopic examination of the ovary on the 5th day after vaginal smear cornification.

The remaining antagonist-treated animals showed persistent vaginal cornification until and including the day of autopsy. On macroscopic examination the ovaries of these rats showed large 'lactational' corpora lutea remaining from the ovulation post partum. In addition, these rats had developed large follicular cysts as described before in cyclic rats treated with mifepristone (van der Schoot et al., 1987a).

On Day 8, the amounts of non-luteal ovarian tissues were similar in all three groups (means \pm s.e.m.: control, $20.1 \pm 1.2 \mathrm{mg}$; mifepristone: $16.8 \pm 1.5 \mathrm{mg}$; onapristone, $19.9 \pm 1.4 \mathrm{mg}$; $P>0 \cdot 05$ ). There were also no differences on Day 17 (means \pm s.e.m.: control, $21.8 \pm 2.9 \mathrm{mg}$; mifepristone, $26.3 \pm 1.5 \mathrm{mg}$; onapristone, $23.9 \pm 3.7 \mathrm{mg} ; P>0.05)$. 


\section{Progesterone antagonists and corpora lutea of the preceding pregnancy}

The results are presented in Table 1. Corpora lutea of the preceding pregnancy decreased in size as lactation advanced. Corpora lutea from antagonist-treated rats were not different in weight from

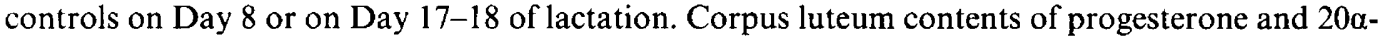
dihydroprogesterone on Day 8 of lactation were greater than those on Day 17; the concentrations per $\mathrm{mg}$ of tissue remained of the same order throughout. There were no significant differences between the 3 groups in any of the characteristics examined.

Table 1. Effect of daily treatment of lactating rats with $2 \mathrm{mg}$ of the progesterone antagonists mifepristone or onapristone on the progesterone and $20 \alpha$-dihydroprogesterone (20a-OHP) contents of CL of pregnancy and from the post-partum ovulation

\begin{tabular}{|c|c|c|c|c|c|c|}
\hline & \multicolumn{3}{|c|}{ Day 8 of lactation } & \multicolumn{3}{|c|}{ Day $17-18$ of lactation } \\
\hline & $\begin{array}{c}\text { CL weight } \\
\text { (mg) }\end{array}$ & $\begin{array}{l}\text { Progesterone } \\
(\mathrm{pmol} / \mathrm{CL})\end{array}$ & $\begin{array}{c}20 \alpha-\mathrm{OHP} \\
(\mathrm{pmol} / \mathrm{CL})\end{array}$ & $\begin{array}{c}\text { CL weight } \\
(\mathrm{mg})\end{array}$ & $\begin{array}{l}\text { Progesterone } \\
(\mathrm{pmol} / \mathrm{CL})\end{array}$ & $\begin{array}{c}20 \alpha-\mathrm{OHP} \\
(\mathrm{pmol} / \mathrm{CL})\end{array}$ \\
\hline \multicolumn{7}{|l|}{ Pregnancy } \\
\hline Control & $1 \cdot 4 \pm 0 \cdot 1^{\mathrm{a}}$ & $32 \pm 5^{a}$ & $408 \pm 60^{3}$ & $0.6 \pm 0 \cdot 1^{a}$ & $25 \pm 4^{\mathrm{a}}$ & $152 \pm 22^{\mathrm{a}}$ \\
\hline Mifepristone & $1 \cdot 4 \pm 0 \cdot 1^{2}$ & $44 \pm 7^{a}$ & $550 \pm 79^{\mathrm{a}}$ & $0 \cdot 4 \pm 0 \cdot 1^{\mathrm{a}}$ & $18 \pm 3^{a}$ & $120 \pm 13^{a}$ \\
\hline Onapristone & $1 \cdot 4 \pm 0 \cdot 1^{\mathrm{a}}$ & $36 \pm 4^{a}$ & $370 \pm 32^{\mathrm{a}}$ & $0.6 \pm 0.1^{a}$ & $20 \pm 5^{a}$ & $152 \pm 13^{\mathrm{a}}$ \\
\hline \multicolumn{7}{|l|}{ Post partum } \\
\hline Control & $1 \cdot 6 \pm 0 \cdot 1^{x}$ & $830 \pm 92^{x}$ & $136 \pm 13^{x}$ & $2 \cdot 1 \pm 0 \cdot 1^{x}$ & $493 \pm 73^{x}$ & $224 \pm 26^{x}$ \\
\hline Mifepristone & $1 \cdot 5 \pm 0 \cdot 1^{x}$ & $541 \pm 64^{x y}$ & $196 \pm 16^{y}$ & $2 \cdot 3 \pm 0 \cdot 2^{x}$ & $410 \pm 67^{x}$ & $487 \pm 76^{y}$ \\
\hline Onapristone & $1 \cdot 6 \pm 0.1^{x}$ & $480 \pm 64^{y}$ & $253 \pm 20^{y}$ & $2 \cdot 3 \pm 0 \cdot 5^{x}$ & $493 \pm 67^{x}$ & $411 \pm 79^{x y}$ \\
\hline
\end{tabular}

Values are mean \pm s.e.m. for $16-20 \mathrm{CL}$ obtained from 8 rats/group.

Within each CL type, values in columns with different superscripts are significantly different, $P<0.05$ at least (oneway ANOVA).

\section{Progesterone antagonists and corpora lutea of lactation}

The results are presented in Table 1. Corpora lutea after post-partum ovulation developed well in all 3 groups. Corpus luteum weight in the three groups was not different on Day 8 or on Day 17. Weights of corpora lutea on Day 17 were significantly higher than those on Day 8. On Day 8 of lactation, the luteal progesterone content in rats treated with onapristone was significantly less than that of controls but those of 20 $\alpha$-dihydroprogesterone were higher. On Day 17-18 of lactation there were no differences in luteal progesterone content between the three groups. However, contents of $20 \alpha$-dihydroprogesterone were higher in the antagonist-treated than in control animals.

Blood concentrations of progesterone, 20a-dihydroprogesterone and prolactin on Days 8 and 17 of lactation

The results are presented in Table 2. On Day 8 of lactation the blood concentrations of all 3 hormones were similar in all 3 groups. Prolactin concentrations were elevated as the result of suckling. Progesterone in blood reflected luteal activity of the lactational corpora lutea as the amounts of progesterone in corpora lutea of the preceding pregnancy were too small to contribute to any significant degree (see Table 1).

On Day 17 of lactation, and with only one ovary from Day 8 of lactation, differences had developed between the 3 groups in the blood concentrations of progesterone and 20 $\alpha$-dihydroprogesterone (Table 2). Interpretation of the differences found on Day 17 is difficult: the ovarian sources of these steroids were different in the $\mathbf{3}$ groups, with control rats showing only the corpora 
Table 2. The blood concentrations of prolactin, progesterone and $20 \alpha$-dihydroprogesterone (20 $\alpha$-OHP) on Days 8 and 17-18 of lactation in rats with litters of 10 pups and treated with mifepristone or onapristone ( $2 \mathrm{mg} / \mathrm{rat} /$ day)

\begin{tabular}{lccccccc}
\hline & \multicolumn{3}{c}{ Day 8 of lactation } & & \multicolumn{3}{c}{ Day 17-18 of lactation $\dagger$} \\
\cline { 2 - 3 } & $\begin{array}{c}\text { Prolactin } \\
(\mu \mathrm{g} / \mathrm{l})\end{array}$ & $\begin{array}{c}\text { Progesterone } \\
(\mathrm{nmol} / \mathrm{l})\end{array}$ & $\begin{array}{c}20 \alpha-\mathrm{OHP} \\
(\mathrm{nmol} / \mathrm{l})\end{array}$ & & $\begin{array}{c}\text { Prolactin } \\
(\mu \mathrm{g} / \mathrm{l})\end{array}$ & $\begin{array}{c}\text { Progesterone } \\
(\mathrm{nmol} / \mathrm{l})\end{array}$ & $\begin{array}{c}20 \alpha-\mathrm{OHP} \\
(\mathrm{nmol} / \mathrm{l})\end{array}$ \\
\hline Control & $418 \pm 141$ & $343 \pm 54$ & $335 \pm 38$ & & $193 \pm 60$ & $232 \pm 20$ & $98 \pm 13$ \\
Mifepristone & $345 \pm 57$ & $363 \pm 67$ & $360 \pm 19$ & & $345 \pm 126$ & $324 \pm 48$ & $158 \pm 19$ \\
Onapristone & $293 \pm 111$ & $328 \pm 29$ & $338 \pm 41$ & & $345 \pm 174$ & $210 \pm 41$ & $136 \pm 13^{*}$ \\
\hline
\end{tabular}

Values are mean \pm s.e.m. for 8 rats/group.

tOnly one ovary present in each animal after unilateral ovariectomy on Day 8 of lactation.

${ }^{*} P<0.05$ compared with control value (one-way ANOVA).

lutea remaining from post-partum ovulation and antagonist-treated rats showing 1 or 2 generations of corpora lutea. The high concentrations of progesterone in blood of the antagonist-treated rats which had only the post-partum corpora lutea present indicate beyond doubt that these corpora lutea had continued to secrete progesterone from early after formation.

\section{Discussion}

The present investigations aimed to examine possible roles of progesterone in the initiation, maintenance or cessation of luteal activity in rats. A number of recent investigations, using progesterone antagonists to uncover such possible roles of progesterone, have provided evidence both in favour and against such role (see 'Introduction', for references).

A major difficulty in the study of potentially direct actions of progesterone antagonists on corpora lutea may be that administration of these agents makes progesterone invisible to the whole physiological system. This 'masking' may initiate events which, only indirectly, result in changed activity of corpora lutea. A possible example is the study of luteal activity in copulationinduced pseudopregnant rats: removal of progesterone action may result in the reduction or even disappearance of the stimulus for prolactin secretion (de Greef \& Zeilmaker, 1978). Insufficient secretion of prolactin may then lead to luteolysis. It is impossible to distinguish direct effects of the antagonists on corpora lutea from indirect actions, resulting from changed prolactin or other pituitary hormone secretion.

The present study aimed to analyse effects of progesterone antagonists on luteal activity by using a system of 'exogenous' (i.e. by suckling infant rats) control of luteal function. Such study required the establishment of the absence of noxious effects of the antagonists on lactational performance.

In accordance with a preliminary study (van der Schoot et al., 1987b) lactational performance, as measured by growth of 10-pup litters, was not affected by progesterone antagonists until Day 10 of lactation. After Day 10 a gradual delay occurred in litter weight gain. However, lactational performance as measured by direct observation of interactions between infants and their mothers was not markedly affected. It is unclear why litters developed growth reduction when their mothers are treated with a progesterone antagonist. There is no reason to assume that progesterone plays any significant role in litter weight gain during established lactation (van der Schoot \& de Greef, 1983). A further study, using ovariectomized lactating rats to compensate for possible differential effects on litter growth of differences in ovarian activity (e.g. Zeilmaker, 1969) induced by the antagonists, revealed a similar difference in litter growth (P. van der Schoot \& E. J. Slappendel, unpublished observations). Diminished litter growth may result from 'side effects' of progesterone antagonists and antagonistic properties to corticosteroid activity (Philibert et al., 1985) may be a 
possible candidate. In general, indeed, effects of 'anti-progestagens' should be viewed with some caution as resulting from the specific blockage of progesterone-dependent phenomena. None of these drugs can be expected to be entirely specific in the dose ranges used (Philibert et al., 1985; van der Schoot et al., 1987a).

Neither of the progesterone antagonists seemed to affect the disappearance of the corpora lutea of gestation during lactation. The disappearance of these corpora lutea takes several weeks. Hormones during early lactation seem to enhance luteal degradation as litter removal results in a diminished rate of disappearance of these structures (Long \& Evans, 1922). However, the antagonists do not affect luteal degradation during normal lactation. It can be concluded that progesterone plays no role in this process as, otherwise, antagonists would have altered its pattern.

Neither of the progesterone antagonists affected structural development of the lactational corpora lutea: size, weight and macroscopic appearance were not affected by mifepristone or onapristone. After unilateral ovariectomy on Day 8 of lactation, corpora lutea in the remaining ovary increased in size and this increase was not affected by treatment with the antagonists. As treatment occurred from the day of post-partum ovulation onwards, the corpora lutea developed, and reacted to unilateral ovariectomy, in an environment in the presence of the antagonists. It seems reasonable to conclude that progesterone has no role or effect on any of the processes involved in the occurrence of these luteal characteristics.

Luteal contents of progesterone and $20 \alpha$-dihydroprogesterone varied to some extent with the experimental procedures. Progesterone contents were significantly reduced on Day 8 of lactation, but not on Day 17-18, in rats treated with onapristone. There appeared a more consistent effect on the luteal contents of $20 \alpha$-dihydro-progesterone on both Day 8 and Day 17-18. The differences in luteal contents on Day 8 were not reflected in differences in the blood concentrations of the two steroids. We therefore suggest that prolonged treatment of lactating rats with a progesterone antagonist does not greatly, if at all, interfere with the normal development and persistence of luteal function.

Failure of treatment to alter markedly corpus luteum development during lactation differs from the reported luteolytic action of these substances on corpora lutea in copulation-induced pseudopregnant rats (Kawano et al., 1988; Singh et al., 1988). However, the experimental design was unable to distinguish between 'direct' and 'indirect' (see 'Introduction') effects of the antagonists on corpora lutea. We therefore suggest that the luteolytic action of progesterone antagonists does not emerge provided that a sufficient luteotrophic stimulus, e.g. through suckling, remains present.

On Day 17 of lactation a number of rats treated with the antagonists had ovulated despite persistent lactation. This observation supports the fact that suckling in rats, by itself, is only temporarily effective in inhibiting pituitary gonadotrophin release and, thereby, ovulation during the lactational period. From earlier experiments it has been proposed that progesterone action underlies inhibition of ovulation during the second half of lactation (Smith \& Neill, 1977). This latter conclusion is corroborated specifically through the present finding of ovulation around Day 13 (range Day 11-15) of lactation. In accordance with earlier results (van der Schoot et al., 1987b), such ovulation did not seem to inhibit progesterone production by the corpora lutea which had been present from the post-partum ovulation. In fact, treatment with a progesterone antagonist seems to provide a way by which corpus luteum degradation can be prevented despite intermittent ovulation.

During normal ovulatory cycles every new ovulation is associated with degradation of the one or more corpora lutea resulting from the previous ovulation. This association, together with atresia of unovulated follicles, underlies the absence of ovarian growth despite continuous follicular growth and corpus luteum formation. The dissociation between ovulation and degradation of the present generation of corpora lutea, as recorded in this study, may be the specific result of the presence of progesterone antagonists. Progesterone may play a critical role in the mechanism underlying luteolysis. Earlier evidence obtained with sheep has also revealed 
dissociation between luteolysis and the next ovulation resulting in accumulation of corpora lutea in the ovaries; interestingly, this experiment also used elimination of progesterone action, albeit through immunization against this hormone rather than through administration of a progesterone antagonist (French \& Spennetta, 1981; Thomas et al., 1987). There may therefore be interspecific generality of the dissociation between luteolysis and the next ovulation through the elimination of progesterone action. Further experiments should be carried out to substantiate this potential effect.

We thank Dr R. DeRaedt (Roussel-Uclaf, Romainville, France) for providing mifepristone; and Dr W. Elger (Schering, Berlin, West Germany) for providing onapristone. Part of the work was performed as a laboratory stage (E.S.) in the programme of the Van Leeuwenhoek Instituut (Delft, The Netherlands).

\section{References}

Asch, R.H. \& Rojas, F.J. (1985) The effects of RU486 on the luteal phase of the rhesus monkey. J. Steroid Biochem. 22, 227-230.

Baulieu, E.E. (1985) Contragestion by antiprogestin: a new approach to human fertility control. In Abortion: Medical Progress and Social Implications (Ciba Fdn Symp. 115), pp. 192-210. Pitman, London.

de Greef, W.J. \& Zeilmaker, G.H. (1978) Regulation of prolactin secretion during the luteal phase in the rat. Endocrinology 102, I 190-1198.

Elger, W., Fähnrich, M., Beier, S., Qing, S.S. \& Chwalisz, K. (1987) Endometrial and myometrial effects of progesterone antagonists in pregnant guinea pigs. Am. J. Obstet. Gynec. 157, 1065-1074.

Elger, W., Esch, A., Fähnrich, M., Beier, S., Riedl, J., Windt-Hanke, F. \& Hasan, S.H. (1988) Antiluteolytic effects of progesterone antagonists (AG) in the cyclic guinea pig are due to inhibition of uterine prostaglandin (PG) synthesis or liberation. Acta endocr., Copenh., Suppl. 287, 40-41.

French, L.R. \& Spennetta, B. (1981) Effects of antibodies to progesterone on reproduction of ewes. Theriogeno$\log y 16,407-418$.

Freeman, M.E. \& Neill, J.D. (1972) The pattern of prolactin secretion during pseudopregnancy in the rat: a daily nocturnal surge. Endocrinology 90, 1292-1294.

Gunnet, J.W. \& Freeman, M.E. (1983) The matinginduced release of prolactin: a unique neuroendocrine response. Endocr. Rev. 4, 44-61.

Herrmann, W., Wyss, R., Riondel, A., Philibert, D., Teutsch, G., Sakiz, E. \& Baulieu, E.E. (1982) Effect d'une stéroide antiprogestérone chez la femme: interruption du cycle menstruel et de la grossesse au début. C. r. hebd. Séanc. Acad. Sci., Paris 294, 933-938.

Kawano, T., Okamura, H., Tajima, C., Fukuma, K. \& Katabuchi, H. (1988) Effect of RU486 on luteal function in the early pregnant rat. J. Reprod. Fert. 83, 279-285.

Kirk, R.E. (1968) Experimental Design: Procedures for the Behavioral Sciences. Brooks/Cole, Belmont.

Lincoln, D.W., Hill, H.A. \& Wakerley, J.B. (1973) The milk-ejection reflex in the rat: an intermittent function not abolished by surgical levels of anaesthesia. J. Endocr. 57, 459 476.
Lincoln, D.W., Hentzen, K., Hin, T., van der Schoot, P., Clarke, G. \& Summerlee, A.J.S. (1980) Sleep: a prerequisite for reflex milk ejection in the rat. Expl Brain Res. 38, 151-162.

Long, J.A. \& Evans, H.M. (1922) The estrous cycle of the rat and its associated phenomena. Mem. Univ. Calif. $5,5-148$.

Philibert, D., Moguilewsky, M., Mary, I., Lecaque, D., Tournemine, C., Secchi, J. \& Deraedt, R. (1985) Pharmacological profile of RU486 in animals. In The Antiprogestin Steroid RU486 and Human Fertility Control, pp. 49-68. Eds E. E. Baulieu \& S. Segal. Plenum Press, New York.

Puri, C.P., Kholkute, S.D., Pongubala, J.M.R., Patil R.K., Elger, W.A.G. \& Jayaraman, S. (1988) Effect of antiprogestin ZK 98.734 on the ovarian cycle, early pregnancy, and on its binding to progesterone receptors in the myometrium of marmoset Callithrix jacchus. Biol. Reprod. 38, 528-535.

Schaison, G., George, M., Lestrat, N., Reinberg, A. \& Baulieu, E.E. (1985) Effects of the antiprogesterone steroid RU486 during midluteal phase in normal women. J. clin. Endocr. Metab. 61, 484489.

Shortle, B., Dyrenfurth, I. \& Ferin, M. (1985) Effects of an antiprogesterone agent, RU486, on the menstrual cycle of the rhesus monkey. J. clin. Endocr. Metab. 60, 731-735.

Singh, G., Singh, M.M., Maitra, S.C., Elger, W., Kalra, V., Upadhyay, S.N., Chowdhury, S.R. \& Kamboj, V.P. (1988) Luteolytic action of two antiprogestational agents (RU-38486 and ZK-98734) in the rat. J. Reprod. Fert. 83, 73-83.

Smith, M.S. \& Neill, J.D. (1977) Inhibition of gonadotropin secretion during lactation in the rat: relative contribution of suckling and ovarian steroids. Biol. Reprod. 17, 255-261.

Thomas, G.B., Oldham, C.M., Hoskinson, R.M., Scaramuzzi, R.J. \& Martin, G.B. (1987) Effect of immunization against progesterone on oestrus, cycle length, ovulation rate, luteal regression and $\mathrm{LH}$ secretion in the ewe. Aust. J. biol. Sci. 40, 307-313.

Uilenbroek, J.Th.J., Woutersen, P.J.A. \& van der Vaart, P.D.M. (1989) Steroid concentrations in rat corpora lutea isolated during the oestrous cycle and pseudopregnancy: effect of induction of ovulation at dioestrus. J. Endocr. 120, 325-330. 
van der Schoot, P. \& de Greef, W.J. (1983) Effect of adrenalectomy on the regulation of the secretion of gonadotrophins and prolactin in the lactating rat. $J$. Endocr. 98, 227-232.

van der Schoot, P., Lankhorst, R.R., de Roo, J.A. \& de Greef, W.J. (1978) Suckling stimulus, lactation and suppression of ovulation in the rat. Endocrinology 103, 949-956.

van der Schoot, P., Bakker, G.H. \& Klijn, J.G.M. (1987a) Effects of the progesterone antagonist RU486 on ovarian activity in the rat. Endocrinology 121, $1375-1382$. van der Schoot, P., Uilenbroek, J., Woutersen, P. \& Bakker, G. (1987b) The progesterone antagonist Mifepristone, a tool for the study of the role of progesterone in regulating ovarian activity in rats. In Neuroendocrinology of Reproduction, pp. 161-168. Eds R. Rolland et al., Elsevier, Amsterdam.

Zeilmaker, G.H. (1969) Milk yield during prolonged lactation in mice: effects of ovariectomy. J. Reprod. Fert. 19, 361-365

Received 24 February 1989 